\title{
DEFINING LEAN CONSTRUCTION CAPABILITY FROM AN AMBIDEXTROUS PERSPECTIVE
}

\author{
Yanqing Fang ${ }^{1}$ and Emmanuel Itodo Daniel ${ }^{2}$
}

\begin{abstract}
Lean construction (LC) is widely used to eliminate waste in the construction industry. However, research on LC capability is lagging relative to other works in the LC field. By exploring relevant literature on the rigid and flexible characteristics of LC, this study proposes for the first time that LC capability is an ambidextrous capability from a paradoxical lens. The investigation reveals that the concept of LC capability has no clear definition and puts forward the view that LC capability is an ambidextrous capability. The study established that LC ambidextrous capability is a paradox which consist of two dimensions - namely LC exploitative capability and LC exploratory capability. LC ambidextrous capability emphasizes striving for a balance between the two capabilities. This study contributes to current knowledge and future application of organizational ambidexterity theory to LC capability development. Regarding contribution to practice, this research would enable LC project practitioners to understand the paradoxical tensions in LC projects, and to how to deal with them. Additionally, this study brings new insight and opens a new debate on how LC ambidextrous capability could develop in the construction field.
\end{abstract}

\section{KEYWORDS}

Lean construction, ambidextrous capability, paradox, exploitation, exploration.

\section{INTRODUCTION}

The construction industry is thought to be riddled with waste and loss of value (Formoso et al., 2015). The concept of lean construction (LC), which was proposed on the basis of lean production theory, is widely used to reduce construction waste (Koskela, 1992). The lean approach is implemented to achieve the rigid targets of projects, such as schedule, quality and cost (Ballard, 1999). In this study, the rigid features of LC refer to the strict requirements for cost reduction, inventory reduction and on-time product delivery that stem from project constraints. Subsequently, several methods and tools have been used to support LC. Just in time (JIT) is a representative tool of lean management, and it reflects the rigidity of the lean approach's requirements on time points and strict requirements on inventory (Liker, 2004). However, the flexibility of LC, which is defined

$\mathrm{PhD}$ Graduate, School of Management Science and Engineering, Tianjin University of Finance and Economics, China. fangyq_lc@sina.com, orcid.org/0000-0003-2989-9737

2 Sr. Lecturer in Constr. Mgmt., School of Arch. and Built Envir., Faculty of Sci. and Engrg., Univ. of Wolverhampton, Wulfruna Street, Wolverhampton, United Kingdom WV1 ILY, E.Daniel2@wlv.ac.uk, orcid.org/0000-0002-5675-1845 
in this study as the characteristics to adjust and adapt to the changing environment, has not received equal attention. With construction projects becoming larger and more complex and the construction environment becoming more dynamic and uncertain, increasing attention has been paid to the adaptive capability or positive response of a project to uncertainty (Ballard \& Tommelein, 2012). From the perspective of complex systems, some variability may be beneficial to the survival of a system (Saurin \& Rooke, 2020), which also reflects LC's adaptation or response to the complex environment. For instance, buffers are designed in a project to prevent the impact of variability and resource starvation (Hopp \& Spearman, 1996). Flexible capability strategies can sometimes be the most valid means to cope with construction variability and contribute to project performance by providing sufficient capability to protect resources from excessive consumption (Horman, 2001). However, the impact of LC capability on project performance is also worthy of further study.

Some studies have shown the rigid and flexible features in LC (Owen et al., 2006). However, these achievements cannot fully explain the whole nature of LC capability. Rigidity and flexibility - a pair of contradictory and symbiotic characteristics of LC - are termed 'LC ambidexterity' in this study. For a better appreciation and understanding of the application of lean in project organisation, lean capability should be viewed as ambidexterity from a paradoxical lens. This view brings in new insight on how to holistically view the impact of LC methodologies in project organisation.

Thus, this research aims to explore the ambidextrous characteristics of LC capability. The following questions are addressed: What is the current understanding of the two characteristics of LC? Are there underlying theories that could explain the relationship between these two characteristics? Can a better understanding of LC ambidextrous capability benefit their application in construction?

The method used in this investigation is a critical literature review. The structure of this paper is as follows. Firstly, a description of the rigidity and flexibility of LC and the understanding of the relationship between the two characteristics in the existing literature is provided, and the standpoint of the LC characteristics in this study is clarified. Secondly, an explanation is given for the theoretical foundation of the viewpoints put forward in this study, and the concept of LC ambidextrous capability is defined. Next, the different applications of LC ambidextrous capability in construction are discussed, and factors that promote the balanced development of LC ambidextrous capability are explained. The paper ends with conclusions and contribution.

\section{CURRENT UNDERSTANDING OF THE RIGIDITY AND FLEXIBILITY OF LEAN CONSTRUCTION}

In the field of manufacturing, discussions have emerged about some ambidextrous elements in lean and its antecedents. For example, Toyota's lean manufacturing system is an example of a 'coordination capability' to achieve a high level of alignment between its production resources or design elements (Fujimoto, 2014). The tension between rational planning and evolutionary adaptation were also emphasised by Fujimoto (2007). The famous Deming Circle contains two attitudes towards variability. Reduce variability through continuous improvement, and cope with variability through continuously improving technology. According to Deming, it is not enough to aim at customer satisfaction on the production line. Rather, it is necessary to go beyond short-term goals, keep learning and take service improvement as the permanent goal (Deming, 1982). 
In the LC field, these two characteristics of LC stem from the main understandings regarding variability in current literature. Variability is very common in construction projects and should be managed effectively (Thomas et al., 2002). It is defined as 'the fact or quality of being variable in some respect; tendency towards, capacity for, variation or change' (Oxford English Dictionary, 2020).

One mainstream view is that all variability should be reduced or eliminated. Based on statistical quality theory and queuing theory, efforts should be made to reduce the variability in significant product characteristics and the temporary variability of production flow (Sacks et al., 2009). There are many discussions on reducing variability. Koskela (2000) proposed that reducing variability within flow processes should be an intrinsic goal. The LPS ${ }^{\mathrm{TM}}$ and the location-based management system are designed to decrease waste, increase productivity and shield construction activities from variability (Seppänen et al., 2010).

Another mainstream view is that not all variabilities should be eliminated. For example, people want buildings to look different (Tommelein, 2015), which requires the system to have the flexibility to adapt to different needs. For another example, the mismatches between supply and demand leads to variability, which is sometimes offset by a combination of buffers (Hamzeh, 2007). Proper buffering can make the project more JIT (Tommelein \& Weissenberger, 1999). In this case, variability leads to more flexible solutions to changing circumstances, which is more conducive to the survival and development of the system.

The two different understandings of variability lead to the rigid and flexible treatment of variability presented in this study. The implication of this treatment is that the concept of LC capability should not only focus on achieving the rigid target alone but should also factor in the flexible characteristics equally because both contribute to the successful delivery of the project. Although the views of Fujimoto and Deming included the elements of the two characteristics of LC, the weakness of their theoretical foundation has led to a lack of attention to the equal treatment of the two characteristics. This research aims to introduce ambidexterity theory into the LC field and provide a theoretical explanation for the two characteristics of LC.

\section{THEORETICAL EXPLANATION}

\section{Paradoxical Thinking}

According to Smith and Lewis (2011, p. 86), a paradox is defined as a series of 'contradictory yet interrelated elements that exist simultaneously and persist over time'. These elements contain potential tensions and react to embrace these tensions simultaneously (Smith \& Lewis, 2011). Dilemma and paradox are sometimes interchanged in conventional use, but there is an important difference between the two concepts. In a dilemma, choices are made after weighing the pros and cons, while the significance of paradox is that such a choice should not be made. The value obtained from paradoxical thinking comes from this duality (Storey \& Salaman, 2009). Paradoxical tensions may exist in various forms at different levels; they may be unique at each level, or a paradox exists simultaneously at all levels, or the tension of paradoxes nested and concatenated at one level gives rise to new tensions at another (Smith \& Lewis, 2011).

Lean projects are temporary production systems designed to maximise value and minimise waste while delivering products (Ballard \& Howell, 2003). Still, some paradoxes remain in LC projects and might be reinforced by lean. For example, one 
paradox is JIT and buffers. Zero inventory is an ideal state. From the raw material to the delivery of the final product to the customer, interruptions will inevitably occur. Therefore, there must be some necessary inventory or buffer (Liker, 2004). A small inventory buffer may be suitable for construction to keep up with installation, but preparing a large buffer comes at a cost. Proper buffering can make the project more JIT (Tommelein \& Weissenberger, 1999). Should we eliminate all buffers? JIT seems to reinforce paradoxical tensions. Another paradox that may be stressed by the lean approach is the paradoxical tension of standard operating procedures versus customised crafted solutions (Eaton et al., 2015). Lean thinking emphasises standardised work. Projects require rigorous standardised procedures to provide repeatable solutions, but when innovative or unexpected project tasks arise, customised crafted solutions are urgently needed, which may result in the dysfunction of standardisation policies (Eaton et al., 2015).

As a paradox is an intrinsic characteristic and dynamic factor of organisations, we need paradoxical thinking to manage paradoxical tensions. Managing paradox does not mean eliminating the paradox but rather tapping its incentive potential. Creatively capturing the two extremes, such as innovation and efficiency, is considered an effective means to manage paradox (Eisenhardt, 2000).

\section{Organisational AMBIDEXTERITY ThEORY}

The concept of ambidexterity was first proposed by Duncan in 1976. It was argued that the management of the 'dual structure' is the core of the ambidexterity concept (Birkinshaw \& Gibson, 2004). Although no unified definition of ambidextrous capability exists, at the organisational level, ambidexterity is generally considered to be a pair of contradictory and symbiotic paradoxical capabilities for organisations to perform different and often competing strategic actions at the same time (Simsek et al., 2009). The most widely used definition is the interpretation of ambidexterity by March (1991), namely exploration and exploitation.

Early research often claimed that ambidexterity is a competitive relationship (Simsek et al., 2009), and the discussion mostly centred on the opposition and conflict between exploratory and exploitative activities. However, the co-existence of exploration and exploitation in the same organisation is achieved by establishing mechanisms for the separation of time and space (Eriksson, 2013). Sequential ambidexterity refers to the temporal separation of exploration and exploitation activities in different sequences while structural ambidexterity emphasises the separation of business units for exploration and exploitation activities (Simsek et al., 2009). In the perspectives of opposition and conflict, the interdependent relationship between exploration and exploitation is ignored. In the context of a highly dynamic environment, sequential and structural ambidexterity has become more and more cumbersome and incapable of responding flexibly to the impact of external environment changes. Birkinshaw and Gibson (2004) put forward the concept of contextual ambidexterity, which is considered to represent a complementary process. Structural ambidexterity is achieved through activities that focus on alignment and adaptability when completed in separate teams or units while contextual ambidexterity is achieved when individuals allocate their time between adaptability-focused and alignment-focused behaviours (Birkinshaw \& Gibson, 2004). Contextual ambidexterity requires the organisation to realise both exploitation and exploration internally and simultaneously and that exploitation and exploration are inseparable, interdependent, mutually integrated and embedded to generate synergy, not just a simple presentation in 
the organisation (Raisch, 2008). The emergence of contextual ambidexterity takes the paradoxical lens, emphasising that the success of the overall organisation depends on simultaneous exploration and exploitation (Smith \& Lewis, 2011). Smith and Tushman (2005) called for the realisation of ambidexterity through, paradoxical thinking. Andriopoulos and Lewis (2009) analysed how paradoxical thinking can promote a virtuous circle of ambidexterity. A paradoxical solution is to seek ambidexterity or ambidextrous organisation form that simultaneously creates tight and loosely coupled organisational structures (Storey \& Salaman, 2009).

\section{DEFINITIONAL ISSUES OF LC CAPABILITY}

\section{Definition of LC Ambidextrous CAPABility}

As revealed by the paradoxical tensions faced by LC project organisations, contextual ambidexterity is required for project organisations to have a better paradoxical solution. Contextual ambidexterity does not mean the separation of structures or sequence; instead, it emphasises striving for a balance between the two capabilities by attempting to allocate time between the activities of the two complementary capabilities (Birkinshaw \& Gibson, 2004). LC capability includes both the ability to achieve the rigid goals of the project and the ability to respond flexibly to the uncertainty of the project, instead of discarding one of the two. It has the characteristics of contextual ambidextrous capability. In this study, LC ambidextrous capability is defined as follows:

\section{LC capability is the capability that an organisation or individual has to achieve LC goals and an ambidextrous capability to solve both conflicting and interdependent problems. It embodies the philosophy, principles and methods of $L C$ and is dedicated to solving the paradoxical tensions in an LC project.}

LC ambidextrous capability represents two capabilities that deal with opposing characteristics. Based on this duality, LC ambidextrous capability should be a twodimensional construct.

\section{Lean Construction CaPability Dimensions}

Just as Fujimoto put forward the perspective of rational planning and evolutionary adaptation, rational planning focuses on efficiency and cost, which are a reflection of rigid capability, while evolutionary adaptation is a process of gradually building capability through experiment and trial and error learning, which is a reflection of flexible characteristics. As the ability to ensure the production schedule is not enough, the ability to produce quickly to order is equally important. It is not enough to achieve short-term benefits because only continuous learning and improvement can ensure the high performance of the production system and achieve the long-term goals (Fujimoto, 2007; Deming, 1982). The views of Fujimoto and Deming have the same underlying structure as what March said concerning ambidextrous dimensions.

According to March (1991), exploitative activities are always connected with the elements of refinement, implementation, selection and efficiency, whereas exploratory activities are always associated with the elements of search, variability, discovery and experimentation. The activities of organisational ambidextrous learning, innovation and adaptability refer to the same underlying constructs of exploration and exploitation but with different labels in different contexts (Raisch \& Birkinshaw, 2008). Referring to March's (1991) ambidextrous dimensions, we divide LC capability into two dimensions: LC exploitative capability and LC exploratory capability. 


\section{The LC exploitative capability dimension}

LC exploitative capability is a rigid capability that tends to eliminate all variabilities to achieve continuous flow, standardisation, modularisation and the ideal state of pursuing zero inventory. Unlike tolerance for variation, it refers to maintaining the consistency and efficiency of results. This capability pays more attention to the use of existing technology and knowledge in the organisation to obtain current benefits.

\section{The LC exploratory capability dimension}

LC exploratory capability is a flexible capability that tends to eliminate the waste caused by the inability to cope with variability. This kind of capability is derived from possessing multi-skilled resources and supplying them in plenty to be capable of moving between functions, absorbing fluctuations of demand while promising the sustainability of the system operation (Horman, 2001). LC exploratory capability also focuses on employee participation, tolerates variation, encourages employee trial and error and focuses on a culture of continuous improvement.

\section{The Dynamic Balance of The Two Dimensions}

In a project life cycle, LC exploitative capability and LC exploratory capability are not permanent, and the two dimensions have dynamic capability characteristics. LC ambidextrous capability is presented as contextual ambidexterity. Requirements for project consistency, short-term efficiency and benefits and project constraints are the driving factors for LC exploitative capability while personalised needs, long-term benefits and continuous improvement are the driving factors for LC exploratory capability.

Under the driving force, the growth of LC exploratory capability can promote a culture of continuous improvement, promote long-term cooperation between suppliers and promote the accumulation of social capital, which is conducive to obtaining long-term benefits to achieve the continuous growth of LC exploitative capability (Eriksson, 2013). The growth of LC exploitative capability can enable short-term goals to be achieved continuously and obtain considerable benefits. It is the necessary economic guarantee for the development of LC exploratory capability, and it is the foundation for the better development of new technologies and products that meet the personalised needs of customers (Eriksson, 2013; March, 1991). The two capabilities exist at the same time and complement each other, thereby forming a virtuous circle, which promotes the LC ambidextrous capability to reach a dynamic balance.

\section{DISCUSSION}

This section further discusses how the application of LC ambidextrous capabilities would benefit construction projects and which elements promote the balanced development of LC ambidextrous capability.

\section{Application of LC Ambidextrous Capability}

The application of LC ambidextrous capabilities to resolve paradoxical situations has been demonstrated in the use of some lean tools. For example, the JIT method of lean, addresses the paradox of quality and efficiency (Storey \& Salaman, 2009). Total quality management realises both customer-oriented and process-oriented requirements, thereby shortening cycle time and saving cost while improving customer satisfaction (Koskela et al., 2019). Deming Circle focuses on quality and efficiency through continuous 
improvement. A mass customisation strategy is designed to provide a variety of products for capturing customer needs while meeting the cost and lead time of mass production (Tillmann \& Formoso, 2008). Other than focusing on the application of a certain tool to solve certain local problems in production management, LC ambidextrous capability can gradually be developed to more rich fields, such as the project organisational area. For example, LC ambidextrous capability can be used to resolve problems caused by the separation of the design and construction phases of a project and balance the contradiction between the interests of the individual and of all parties. Eriksson (2013) discussed the performance of structural ambidexterity, sequential ambidexterity and contextual ambidexterity in solving problems existing in the construction project organisation. Sequential or structural separation, such as focusing more on exploration in the early stages of a project and on exploitation at the end of a project during implementation, is more suitable for stable environments. The structural solutions to the problems caused by the separation of design and construction are insufficient, but contextual ambidexterity provides viable solutions to better balance those problems (Eriksson 2013).

\section{LC AmbideXterity Promotion Factors}

Gibson and Birkinshaw (2004) stated that a successful organisation should balance hard elements, such as disciplines, and stretch with soft elements, such as trust and support, in the organisational context. This section exemplifies and discusses below three factors that promote LC ambidextrous capability, because these factors can promote the dynamic balance of rigidity (exploitative) and flexibility (exploratory) of LC capability.

Commitment and cooperation: A better commitment network promotes mutual trust, information transparency and knowledge sharing among members as well as creates a better atmosphere of innovation to better promote the improvement of LC exploratory capability. The trust relationship continues to accumulate with the commitment network and close cooperation (Viana et al., 2011), and LC exploitative capability and LC exploratory capability promote and improve each other to achieve a dynamic balance. A common approach is the integrated project delivery collaboration model. Integration of lean and building information model concepts can also promote communication and collaboration (Sacks et al., 2009). LPS ${ }^{\mathrm{TM}}$ enables a short feedback circle of planning and corresponding, requires team members to make a solid commitment and encourages the acceptance of diverse perspectives in making decisions to avoid greater losses (Saurin \& Rooke, 2020).

Considering the project organisation as a production system: The system view is a more holistic and integrated view, such as the Lean Project Delivery System ${ }^{\mathrm{TM}}\left(\mathrm{LPDS}^{\mathrm{TM}}\right)$. Ballard (2008) emphasised the interdependence between functions and the integration of information and resources. The LPS ${ }^{\mathrm{TM}}$ is an important system tool that emphasises the authorisation of employees to plan and arrange specific tasks. However, planning activities also include buffering of work activities and focusing on overall efficiency rather than local efficiency. Functional resonance analysis is a method that can model variability propagation in LC (Saurin, 2016), thereby better predicting uncertainty and making up for the lack of flexibility from a systematic perspective in the plan. These system methods enable the short-term goals of a project to be effectively achieved, helping improve the LC exploitative capability. At the same time, the system view helps exploratory quality management practices focus on overall costs rather than local costs. It also focuses on learning feedback, buffer management, resilience engineering and 
sustainability that will help improve LC exploratory capability. LC exploitative capability and exploratory capability complement each other to achieve a dynamic balance.

A culture that values organisational learning and continuous improvement: Learning organisations can respond to new challenges more quickly and flexibly (Jiménez-Jiménez \& Sanz-Valle, 2011). Disciplines and standards are used to guide the project to perform specific tasks, but standardisation is not a fixed implementation or a fixed layer. The standardisation of the LC project organisation is the basis for continuous improvement and a tool for empowering employees to achieve better innovation based on standards. The standardised process is a powerful guarantee to eliminate variability and improve product quality (Liker, 2004). It developed the LC exploitative capability. Organisational learning and continuous improvement are conducive to project members to continue exploring and innovating based on the implementation of standard operating procedures and the elimination of outdated and rigid standard processes. The two complement each other, and standardisation and continuous improvement are mutually reinforcing.

\section{CONCLUSIONS AND FUTURE RESEARCH}

This research explores the ambidextrous characteristics of LC capability by reviewing the literature in the fields of LC, organisational ambidexterity and paradox in order to identify what LC ambidextrous capability is and how it benefits LC. The research finds that the rigidity and flexibility of LC stem from the main understandings of variability in current literature. The investigation reveals that the concept of LC capability has no clear definition, and it puts forward the view that LC capability is an ambidextrous capability. The study establishes that LC ambidextrous capability is a paradox consisting of two dimensions, namely LC exploitative capability and LC exploratory capability, which breaks the traditional view that LC capability is biased toward exploitation or exploration. The study argues that the exploitative and exploratory capabilities of LC are interdependent and should be achieved in a dynamic balance.

This study contributes to the current knowledge and future application of organisational ambidexterity theory to LC capability development. Different contradictory situations arise during the execution of a project. For example, should the focus be on efficiency or innovation? Should it be on short-term performance or longterm performance? Although Fujimoto, Deming and others already have some ideas that take the rigidity and flexibility of LC into consideration, they have not given the theoretical explanation behind the specific phenomenon. Given the lack of theoretical foundations, the understanding of the two characteristics may be insufficient and the project paradoxes may not be properly handled. Through the introduction of organisational ambidextrous theory, the definition of LC capability is clarified. This study provides theoretical guidance for practitioners to understand the ambidextrous characteristics of LC capability, clarifies why it is necessary to balance the relationship between LC exploitation capability and LC exploration capability and identifies the factors that promote the balance of LC ambidextrous capability.

This study brings new insight and opens a new debate on how LC ambidextrous capability could develop in the construction field. More applications at the organisation level need to be explored in future research, and the organisational characteristics that are most conducive to the balanced development of LC ambidextrous capability require further study using live real-life case studies. This research direction would be the future focus of the authors. 


\section{REFERENCES}

Andriopoulos,C.\& Lewis,M. (2009).Exploitation-exploration tensions and organizational ambidexterity: Managing paradoxes of innovation. Organ. Sci., 20 (4), 696-717.

Ballard, G. (2008). The lean project delivery system: An update. Lean Cont. J. , 1-19.

Ballard, G. (1999). Improving Work Flow Reliability. 7th IGLC Conf. USA, 275-286.

Ballard, G.,\&Howell, G. (2003). Lean project management. Build.Res.Inf.,31(2),119-133.

Ballard, G., \& Tommelein, I. (2012). Lean management methods for complex projects. Eng. Proj. Organ. J., 2(1-2), 85-96.

Birkinshaw, J., \& Gibson, C. (2004). Building ambidexterity into an organization. MIT SLOAN Manag. Rev., 45(4), 47.

Deming, W. E. (1982). Out of the crisis, Massachusetts Institute of Technology, Cambridge, MA.

Eaton, B., Elaluf-Calderwood, S., Sørensen, C., \& Yoo, Y. (2015). Distributed tuning of boundary resources: The case of Apple's iOS service system. MIS Q. Manag. Inf. Syst., $39(1), 217-243$.

Eisenhardt, K. M. (2000). Paradox, Spirals, Ambivalence: the New Language of Change and Pluralism. Acad. Manag. Rev., 25(4), 703-705.

Eriksson, P. E. (2013). Exploration and exploitation in project-based organizations: Development and diffusion of knowledge at different organizational levels in construction companies. Int. J. Proj. Manag., 31(3), 333-341.

Formoso, C., Bølviken, T., Rooke, J., \& Koskela, L. (2015). A conceptual framework for the prescriptive causal analysis of construction waste. 23rd IGLC Conf. of the Int. Group for Lean Const., Perth, Australia, 454-461.

Fujimoto, T., Miller, B. (2007). Competing to Be Really, Really Good: the behind-thescenes drama of capability-building competition in the automobile industry (Vol. 22). Tokyo: International House of Japan.

Fujimoto, T. (2014). The long tail of the auto industry life cycle. J. Prod. Innov. Manag., 31(1), 8-16.

Hamzeh, F., Tommelein, I., Ballard G, et al (2007). Logistics Centers to Support ProjectBased Production in the Construction Industry. 15th IGLC Conf. USA, 181-191.

Hopp, W. J., \& Spearman, M. L. (1996). Factory physics: foundations of manufacturing management. Irwin/McGraw-Hill.

Horman, M. J. (2001). Modeling the Effects of Lean Capacity Strategies on Project Performance. Proc. 9th Annual Conf. of the Int. Group for Lean Const., Singapore.

Jiménez-Jiménez, D., \& Sanz-Valle, R. (2011). Innovation, organizational learning, and performance. J. Bus. Res., 64(4), 408-417.

Koskela, L. (1992). Application of the New Production Philosophy to Construction. CA. Technical Report No. 72. CIFE.

Koskela, L. (2000). An exploration towards a production theory and its application to construction. In VTT Publications.

Koskela, L., Tezel, A., \& Patel, V. (2019). Theory of Quality Management: Its Origins and History. $27^{\text {th }}$ IGLC Conference, Dublin, Ireland, 1381-1390.

Liker, J. (2004). The Toyota Way: Fourteen Management Principles From the World's Greatest Manufacturer. In McGraw-Hill.

March, J. G. (1991). Exploration and Exploitation in Organizational Learning. Organ. Sci., 2(1), 71-87.

Oxford English Dictionary, 2020. Accessed March 24, 2021. https://www.oed.com/view/Entry/221513?redirectedFrom=variability\#eid. 
Owen, R., Koskela, L., Henrich, G., \& Codinhoto, R. (2006). Is Agile Project Management Applicable to Construction? 14th IGLC Conference, Chile, 51-66.

Raisch, S., \& Birkinshaw, J. (2008). Organizational ambidexterity: Antecedents, outcomes, and moderators. J. Manage., 34(3), 375-409.

Sacks, R., Dave, B. A., Koskela, L., \& Owen, R. (2009). Analysis framework for the interaction between lean construction and Building Information Modelling. 17th IGLC Conference, Taipei, 221-234.

Saurin, T., \& Rooke, J. (2020). The Last Planner® System as an approach for coping with the complexity of construction projects. In P. Tzortzopoulos, M. Kagioglou, \& L. Koskela (Eds.), Lean Construction: Core Concepts and New Frontiers (1st ed., pp. 325-340). Routledge.

Saurin, T. (2016). The FRAM as a Tool for Modelling Variability Propagation in Lean Construction. 24th Annual Conf. of the Int. Group for Lean Const., USA.

Seppänen, O., Ballard, G., \& Pesonen, S. (2010). The combination of last planner system and location-based management system. Lean Const. Journal, 2010, 43-54.

Simsek, Z., Heavey, C., Veiga, J. F., \& Souder, D. (2009). A Typology for Aligning Organizational Ambidexterity's Conceptualizations, Antecedents, and Outcomes. $J$. Manag. Stud., 46(5), 864-894.

Smith, W., \& Lewis, M. (2011). Toward a theory of paradox: A dynamic equilibrium model of organizing. Acad. Manag. Rev., 36(2), 381-403.

Smith,W.,\&Tushman,M.L.(2005). Managing strategic contradictions: A top management model for managing innovation streams. Organ. Sci., 16 (5), 522-536.

Storey, J., \& Salaman, G. (2009). Managerial dilemmas. Exploiting paradox for strategic leadership (1. Aufl.). Wiley-Blackwell.

Thomas, H. R., Horman, M. J., de Souza, U. E. L., \& Zavřski, I. (2002). Reducing Variability to Improve Performance as a Lean Construction Principle. J. Constr. Eng. Manag., 128(2), 144-154.

Tillmann, P. A., \& Formoso, C. T. (2008). Opportunities to adopt mass customisation A case study in the Brazilian house building sector. 16 ${ }^{\text {th }}$ IGLC Conf., UK, 447-458.

Tommelein, I. D. (2015). Journey toward Lean Construction : Pursuing a Paradigm Shift in the AEC Industry. J. of Const. Engr. and Management, 141(1970), 1-12.

Tommelein, I. D., \& Weissenberger, M. (1999). More just-in-time: location of buffers in structural steel supply and construction processes. Proc. 7th Annual Conf. of the Int. Group for Lean Const., Berkeley, California, USA, 109-120.

Viana, D. D., Formoso, C. T., \& Isatto, E. L. (2011). Modelling the network of commitments in the last planner system. Lean Const. Journal, 55-67. 